\title{
CT interpretation of craniofacial anomalies: a comparative analysis by undergraduate dental students
}

\section{Interpretação de anomalias craniofaciais em TC. Análise comparativa por alunos de graduação em Odontologia}

\author{
Bruno Felipe Gaia* \\ Andréia Perella** \\ Ana Cláudia Ballet de Cara* \\ José Leopoldo Ferreira Antunes*** \\ Marcelo Gusmão Paraiso Cavalcanti ${ }^{* * * *}$
}

\begin{abstract}
The aim of this study was to evaluate the accuracy and reproducibility of computed tomography (CT) image interpretation made in axial slices (2D-CT) and 3D reconstructed images (3D-CT) of patients with craniofacial anomalies. The analyses were made by undergraduate dental students, and compared with the diagnoses considered upon surgical intervention. Computed tomography of 43 patients were analyzed independently by three calibrated examiners (undergraduate students) with, respectively, one, two, and three semesters of experience in craniofacial CT training and interpretation. The analysis of 2D-CT and 3D-CT images were performed at distinct times using an independent workstation associated with a specific computer graphics software for volumetric images. The analysis of inter-examiner agreement and of the agreement between observers and the gold standard was performed using the Kappa test. The accuracy evaluation presented a progressively higher value for examiners with progressively broader experience in 2D-CT and 3D-CT image interpretation. 3D-CT analyses allowed a higher interexaminer agreement $(1-0.896)$ than $2 \mathrm{D}-\mathrm{CT}$ analyses $(1-0.614)$. 3D-CT was considered more precise and accurate than 2D-CT for all students' evaluations. The reproducibility and accuracy varied according to the experience in CT interpretation, and the most experienced student achieved results closer to the gold standard.
\end{abstract}

DESCRIPTORS: Tomography; Face; Craniosynostosis; Craniofacial abnormalities.

\begin{abstract}
RESUMO: O propósito desta pesquisa foi avaliar a habilidade de alunos de graduação na análise de pacientes portadores de anomalias craniofaciais usando imagens de tomografia computadorizada (TC) em cortes axiais (2D-TC) e em terceira dimensão (3D-TC). A análise foi realizada por alunos de graduação em Odontologia, em comparação com o diagnóstico efetuado no ato operatório. Tomografias computadorizadas de 43 pacientes foram analisadas, independentemente, por três alunos de graduação previamente calibrados, com respectivamente um, dois e três semestres de tempo de experiência em interpretação de TC. As análises das imagens em 2D-TC e em 3D-TC foram obtidas em tempos e ocasiões distintos por meio de uma estação de trabalho independente utilizando-se um programa específico para imagens volumétricas. Para análise de concordância entre os observadores e destes com o diagnóstico definitivo foi utilizado o teste estatístico Kappa. Os valores de acurácia foram maiores quanto maior o tempo de experiência em interpretar imagens em 2D-TC e em 3D-TC. As análises em 3D-TC apresentaram indicadores mais elevados de concordância entre os examinadores $(1-0,896)$ que as análises em 2D-TC $(1-0,614)$. A 3D-TC foi considerada mais precisa e acurada em relação à 2D-TC na avaliação dos três alunos. A concordância entre os examinadores e entre estes e o diagnóstico variou de acordo com o tempo de treinamento em TC, sendo o aluno mais experiente aquele que obteve resultados mais próximos ao diagnóstico.
\end{abstract}

DESCRITORES: Tomografia; Face; Craniossinostose; Anormalidades craniofaciais.

\section{INTRODUCTION}

The normal development of the face depends on a perfect synchrony between the activity of the growth centers and associated structures. Any interference may change the correct order of progression and cause defects or deficiency on growth and development patterns ${ }^{12}$. Abnormal craniofa- cial morphology observed in patients with premature closure of the cranial suture has long been attributed to changes in growth patterns, which produce anomalies such as bossing, bulges and prominences ${ }^{12,15}$. During normal ontogeny, there is a chronologic progression until the cessation of

\footnotetext{
*Undergraduate Students; **Dental Practice Volunteer; ***Professor, Department of Social Dentistry; ****Professor, Department of Radiology - School of Dentistry, University of São Paulo.
} 
Gaia BF, Perella A, Cara ACB, Antunes JLF, Cavalcanti MGP. CT interpretation of craniofacial anomalies: a comparative analysis by undergraduate dental students. Braz Oral Res 2005;19(1):58-62.

growth at the various cranial syndesmoses and their transformation into synostoses ${ }^{9}$. Although there is a typical range of biological variations in the chronologic timing of suture closure, premature closure is termed craniosynostosis ${ }^{9}$.

Craniosynostosis (the process) is a term currently used to describe the premature fusion of cranial sutures, although craniostenosis (the result) more accurately describes this pathological entity. When craniosynostosis occurs, growth is restricted at the affected suture, whereas compensatory growth occurs elsewhere ${ }^{15}$. Deformities vary according to type, intensity, extension, chronological time and etiological agent. Furthermore, deformities also depend on individual susceptibility, and the involvement of the growth center area may alter the abnormalities ${ }^{12}$.

The recent advances in computer hardware and software of 3D imaging by computed tomography $(\mathrm{CT})$ scans of craniofacial anomalies have been routinely used by most medical centers to define the individual aspects of complex anatomy, plan interventions and follow the results of such complex pathologies ${ }^{2,5,8,11,13,16,17}$. The defects can be exactly located by CT scans using three-dimensional reconstructed images $5,7,10,11,16,17$.

The purpose of the present study was to compare levels of agreement between undergraduate dental students on image interpretation made in axial slices (2D-CT) and 3D-CT images for patients with craniofacial anomalies.

\section{MATERIALS AND METHODS}

The study population consisted of 43 patients, with craniofacial anomalies, with or without craniosynostosis, who were submitted to computed tomography (Toshiba X/Press, Toshiba Medical, Tustin, CA, USA) under the following protocol: $3 \mathrm{~mm}$ axial slices, $1.5 \mathrm{~mm}$ table feed and $1.5 \mathrm{~mm}$ reconstructed slice interval, in 1 second and 512 x 512 matrix.

The images were analyzed by three trained and calibrated examiners (undergraduate dental students), independently, with experience in CT interpretation of one (examiner 3), two (examiner 2) or three (examiner 1) semesters. The analyses of the 2D-CT and 3D-CT images were carried out at distinct times. Analyses consisted in identifying the presence or absence of premature closure of cranial sutures including: Metopic, Unicoronal, Bilateral coronal, Sagittal, and Unilateral lambdoid ones. Bilateral lambdoid sutures were not included in this study because we did not have cases of this abnormality. The examiners had no knowledge of the patient's clinical history, name, age or gender.

The original CT data was transferred to a Workstation (DELL hardware Precision 420 Windows NT 4.0, Austin, Texas, USA) with Vitrea ${ }^{\circledR}$ version 2.3 software (Vital Images Inc., Plymouth, MN, USA), for axial (2D-CT) and 3D volume rendering reconstructed image analyses. The $2 \mathrm{D}-\mathrm{CT}$ images were analyzed only on axial slices. Software tools were used to allow the visualization and interpretation of tomographic slices from the orbital region until the vertex (Figures $1 \mathrm{a}$ and 2a). 3D reconstruction was analyzed and image manipulation was performed to allow improved visualization of the craniosynostosis. 3D volume rendering technique associated with a computer graphics system offers a wide choice of software tools, which also allows segmentation of the region of interest, "fly through" techniques, image rotation and translation, application of different color tables, contrast and transparency levels based on CT density. The gold standard for this study was considered the surgical intervention.

The 3D-CT images were analyzed according to the following protocol: craniofacial CT, 3D surface with color and window level - soft bone. The transparency level was in maximum degree to perform 2D analysis in order to avoid the 3D image visualization. Software tools were used to allow the rotation and translation of the images (Figures $1 \mathrm{~b}$, $1 \mathrm{c}, 1 \mathrm{~d}, 2 \mathrm{~b}, 2 \mathrm{c}$ and $2 \mathrm{~d}$ ).

The statistical analysis was carried out using the Kappa test ${ }^{14}$.

\section{RESULTS}

Results in Table 1 show the sensitivity assessment (i.e., the Kappa statistics of diagnoses in agreement with the gold standard) in 3D-CT and 2D-CT. Values ranging from 0.8 to 1 mean a good agreement between each examiner and the gold standard. (Table 1)

The most experienced examiner (examiner 1) presented the best results on image interpretation for both 3D-CT and 2D-CT images, and 3D-CT was the most sensitive method for all examiners. Observation of the bilateral coronal sutures allowed higher agreement with the gold standard, followed by metopic sutures and unicoronal sutures.

Table 2 shows the reproducibility (i.e., the agreement of inter-examiner diagnoses) of 3D-CT and 2D-CT analysis.

Table 2 indicates that a higher agreement between examiners was found for 3D-CT analysis. It also shows that better results of agreement and 
Gaia BF, Perella A, Cara ACB, Antunes JLF, Cavalcanti MGP. CT interpretation of craniofacial anomalies: a comparative analysis by undergraduate dental students. Braz Oral Res 2005;19(1):58-62.

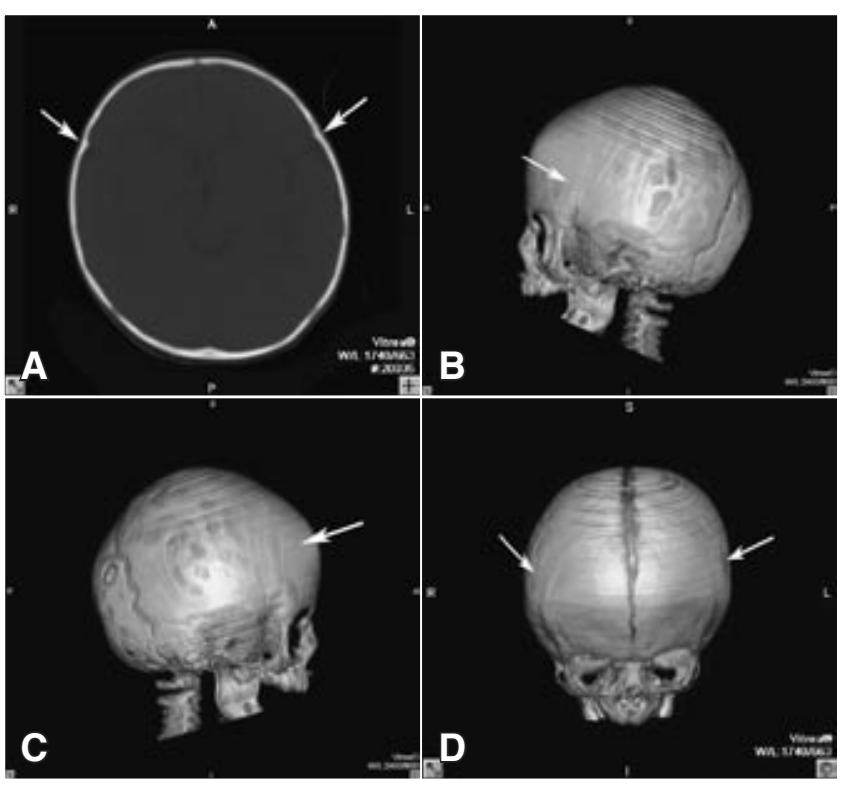

FIGURE 1 - Patient with bilateral coronal synostosis: 2D-CT axial slice shows a closed bilateral coronal suture (arrows) (A); 3D-CT: left lateral view (B), right lateral view (C) and frontal view (D) (arrows) demonstrate the premature closure of the bilateral coronal suture.

TABLE 1 - Examiner sensitivity for all studied sutures in 3D-CT and 2D-CT. Fields with "-" denote that the examiner failed to identify positive cases.

\begin{tabular}{c|c|c|c}
\hline \hline $\begin{array}{c}\text { Analytical } \\
\text { method }\end{array}$ & Examiner 1 & Examiner 2 & Examiner 3 \\
\hline
\end{tabular}

\begin{tabular}{l|c|c|c}
\hline \multicolumn{4}{c}{ 3D-CT } \\
\hline Unicoronal & 1.000 & 0.909 & 0.807 \\
\hline $\begin{array}{l}\text { Bilateral } \\
\text { coronal }\end{array}$ & 1.000 & 1.000 & 1.000 \\
\hline $\begin{array}{l}\text { Unilateral } \\
\text { lambdoid }\end{array}$ & 1.000 & 1.000 & - \\
\hline Sagittal & 0.896 & 0.896 & 0.726 \\
\hline Metopic & 1.000 & 1.000 & 0.870 \\
\hline \multicolumn{4}{|c}{ 2D-CT }
\end{tabular}

\begin{tabular}{l|c|c|c}
\hline Unicoronal & 0.909 & 0.728 & 0.691 \\
\hline $\begin{array}{l}\text { Bilateral } \\
\text { coronal }\end{array}$ & 0.788 & 0.890 & 1.000 \\
\hline $\begin{array}{l}\text { Unilateral } \\
\text { lambdoid }\end{array}$ & 0.656 & 0.656 & - \\
\hline Sagittal & 0.614 & 0.688 & 0.541 \\
\hline Metopic & 1.000 & 0.758 & 0.662 \\
\hline \hline
\end{tabular}

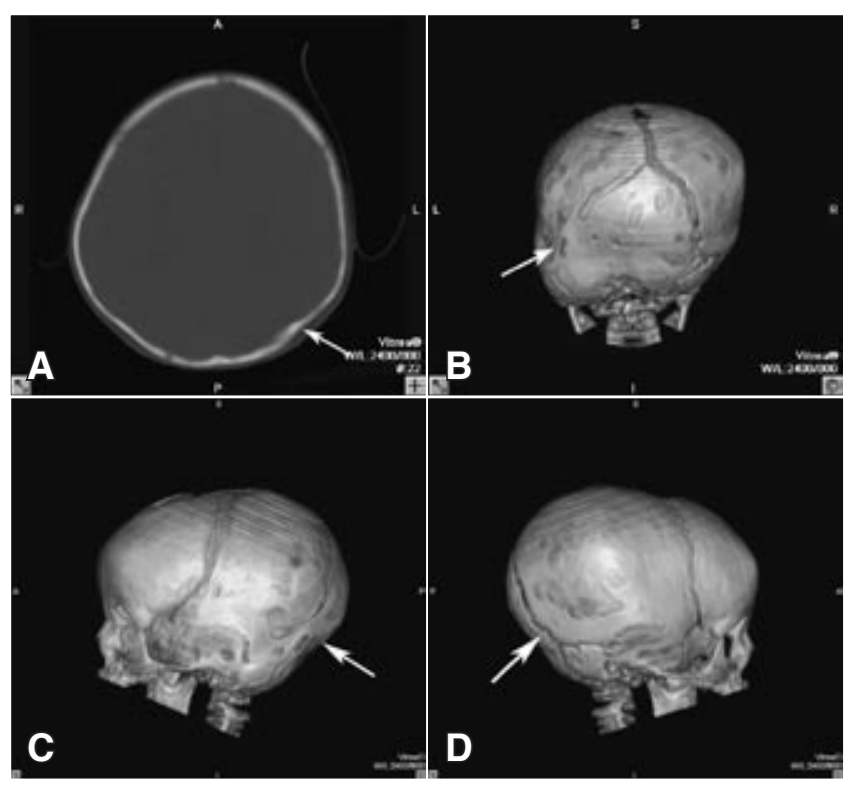

FIGURE 2 - Patient with left unilateral lambdoid synostosis: 2D-CT axial slice depicts a closure of the left lambdoid suture (arrow) (A); 3D-CT images show in rear (B) and left lateral (C) (arrows) views the left lambdoid suture premature closure. Right lateral (D) view shows the normal lambdoid suture (arrow)

TABLE 2 - Statistical analysis for inter-examiner reproducibility for all sutures studied in 3D-CT and 2DCT. Fields with "-" denote that the examiner failed to identify positive cases.

\begin{tabular}{c|c|c|c}
\hline \hline $\begin{array}{c}\text { Analytical } \\
\text { method }\end{array}$ & $\begin{array}{c}\text { Examiner 1 } \\
\text { versus } \\
\text { Examiner 2 }\end{array}$ & $\begin{array}{c}\text { Examiner 1 } \\
\text { versus } \\
\text { Examiner 3 }\end{array}$ & $\begin{array}{c}\text { Examiner 2 } \\
\text { versus } \\
\text { Examiner 3 }\end{array}$ \\
\hline
\end{tabular}

\begin{tabular}{l|c|c|c}
\hline \multicolumn{4}{c}{ 3D-CT } \\
\hline Unicoronal & 0.909 & 0.807 & 0.896 \\
\hline $\begin{array}{l}\text { Bilateral } \\
\text { coronal }\end{array}$ & 1.000 & 1.000 & 1.000 \\
\hline $\begin{array}{l}\text { Unilateral } \\
\text { lambdoid }\end{array}$ & 1.000 & - & - \\
\hline Sagittal & 1.000 & 0.632 & 0.632 \\
\hline Metopic & 1.000 & 0.870 & 0.870 \\
\hline
\end{tabular}

\begin{tabular}{l|c|c|c}
\hline \multicolumn{4}{c}{ 2D-CT } \\
\hline Unicoronal & 0.806 & 0.775 & 0.775 \\
\hline $\begin{array}{l}\text { Bilateral } \\
\text { coronal }\end{array}$ & 1.000 & 0.788 & 0.788 \\
\hline $\begin{array}{l}\text { Unilateral } \\
\text { lambdoid }\end{array}$ & 1.000 & - & - \\
\hline Sagittal & 0.728 & 0.401 & 0.463 \\
\hline Metopic & 0.758 & 0.662 & 0.469 \\
\hline \hline
\end{tabular}


Gaia BF, Perella A, Cara ACB, Antunes JLF, Cavalcanti MGP. CT interpretation of craniofacial anomalies: a comparative analysis by undergraduate dental students. Braz Oral Res 2005;19(1):58-62.

higher agreement were achieved when a most experienced examiner (Examiner 1 versus Examiner 2) performed the analysis.

\section{DISCUSSION}

The diagnosis and treatment planning of abnormalities in the craniofacial complex are limited when only standard radiography is used, due to lack of dimensional accuracy, image distortion, and the presence of superimposed structures ${ }^{1,11}$. However, currently, three-dimensional computed tomography has improved diagnostic performance ${ }^{5,6,16,17}$. Comprehensive understanding of sutural anatomy is very important for the diagnosis and potential surgical correction of craniosynostosis $^{5,7,10,12,16,17}$.

The most recent approaches to the three-dimensional study of growth have come from the field of imaging. Levi et al. ${ }^{6}$ (2002) used CT scans to reproduce the patient's malformed skull as a phantom to provide information about the clinical case, helping the treatment planning and also as an excellent teaching method for residents.

The results of our study are in agreement with those found in the related literature ${ }^{1,2,7,8,11,16,17}$, showing that the gain in image quality with $3 \mathrm{D}$ $\mathrm{CT}$ is higher than with $2 \mathrm{D}-\mathrm{CT}$ images. The former images allow any examiner, experienced in CT image interpretation or not, to perform an easy and improved identification of abnormalities. The most experienced examiner showed values of agreement with the gold standard between 0.896 and 1 for 3D-CT and 0.614 and 1 for 2D-CT analysis, confirming the greater value of the volumetric images for that diagnostic task.

Professional experience is a fundamental requirement for a correct diagnosis. When the professional has had experience in image visualization, greater accuracy is observed for two-dimensional and three-dimensional computed tomography interpretation ${ }^{1,11,16,17}$. This was in agreement with our study, where examiner 1 (three semesters of experience in image interpretation) achieved the most accurate results, followed by examiner 2 (two semesters) and examiner 3, who had one semester of experience in computed tomography image interpretation. Similar results were found by Vannier et $a l .{ }^{16}$ (1989), when studying the value of 3D-CT in craniosynostosis diagnosis; Pilgram et al. ${ }^{11}$ (1989), in their studies of image quality and correctness in diagnosis; and Vannier et al. ${ }^{17}$ (1994), whose studies showed that experienced examiners can achieve nearly perfect diagnoses in all image modalities.
The influence of experience in the reproducibility of diagnoses was better demonstrated when we made a comparison between the examiners. Examiner one (three semesters of experience in image interpretation) versus examiner two (two semesters of experience) presented the highest values of agreement (0.909 - 1 (3D analysis) and $0.728-1$ (2D analysis)).

Regarding the identification of affected sutures, for both 3D and 2D analyses, the identification of the Bilateral coronal suture had the best accuracy, followed by that of Metopic, Unicoronal, Sagittal and Unilateral lambdoid sutures. We believe that these results were found because the bilateral aspects cause higher alterations in the shape of the skull, which is responsible for marked asymmetry, although specific studies must be developed to test this hypothesis.

Cerovac et al. ${ }^{4}$ (2002) stated that a correct diagnosis based on clinical findings was made in $100 \%$ of the cases analyzed by an experienced clinician, and that $\mathrm{CT}$ scans with 3D reconstructions provided diagnostic confirmation in $100 \%$ of the patients with complex craniosynostosis. Cavalcanti, Vannier ${ }^{3}$ (1998) emphasized that 3D-CT imaging is a complementary modality to $2 \mathrm{D}-\mathrm{CT}$ in maxillofacial diagnosis. Our experience shows that the first image interpretations have to be done on axial, coronal and sagittal slices (2D-CT), avoiding the negative influence that $3 \mathrm{D}$ reconstruction may exert. These methods enhance the accuracy of diagnostic decisions and instruct the selection of the most appropriate treatment plan.

\section{CONCLUSIONS}

$3 \mathrm{D}-\mathrm{CT}$ is a more accurate method than $2 \mathrm{D}$ CT for image interpretation among undergraduate Dental students with experience or not. The time of experience in image interpretation is relevant for examiners to make a correct diagnosis when a volumetric imaging modality is used, especially the $3 \mathrm{D}$ volume rendering technique using an independent workstation.

\section{ACKNOWLEDGMENTS}

The support for this research was provided by grants from the National Council for Scientific and Technological Development (CNPq) (309331/20030 - Marcelo Gusmão Paraiso Cavalcanti) and CNPq/PIBIC (Institutional Program for Scientific Initiation Scholarships) (undergraduate student Bruno Felipe Gaia). 
Gaia BF, Perella A, Cara ACB, Antunes JLF, Cavalcanti MGP. CT interpretation of craniofacial anomalies: a comparative analysis by undergraduate dental students. Braz Oral Res 2005;19(1):58-62.

\section{REFERENCES}

1. Alder ME, Deahl ST, Matteson SR. Clinical usefulness of two-dimensional reformatted and three-dimensionally rendered computerized tomographic images: literature review and a survey of surgeons' opinions. J Oral Maxillofac Surg 1995;53(4):375-86.

2. Cavalcanti MG, Vannier MW. Quantitative analysis of spiral computed tomography for craniofacial clinical applications. Dentomaxillofac Radiol 1998;27(6):344-50.

3. Cavalcanti MG, Vannier MW. The role of three-dimensional spiral computed tomography in oral metastases. Dentomaxillofac Radiol 1998;27:203-9.

4. Cerovac S, Neil-Dwyer JG, Rich P, Jones BM, Hayward RD. Are routine preoperative CT scans necessary in the management of single suture craniosynostosis? $\mathrm{Br} \mathrm{J}$ Neurosurg $2002 ; 16(4): 348-54$.

5. Leboucq N, Montoya P, Martinez Y, Castan P. Value of 3D imaging for the study of craniofacial malformations in children. J Neuroradiol 1991;18(3):225-39.

6. Levi D, Rampa F, Barbieri C, Pricca P, Franzini A, Pezzotta $\mathrm{S}$. True 3D reconstruction for planning of surgery on malformed skulls. Childs Nerv Syst 2002;18(12):705-6.

7. Medina LS. Three-dimensional CT maximum intensity projections of the calvaria: a new approach for diagnosis of craniosynostosis and fractures. AJNR Am J Neuroradiol 2000;21(10):1951-4.

8. Neumann K, Moegelin A, Temminghoff M, Radlanski RJ, Langford A, Unger $\mathrm{M}$, et al. 3D-computed tomography: a new method for the evaluation of fetal cranial morphology. J Craniofac Genet Dev Biol 1997;17(1):9-22.
9. Ohman JC, Richtsmeier JT. Perspectives on craniofacial growth. Clin Plast Surg 1994;21(4):489-99.

10. Ono I, Ohura T, Narumi E, Kawashima K, Matsuno I, Nakamura S, et al. Three-dimensional analysis of craniofacial bones using three-dimensional computer tomography. J Craniomaxillofac Surg 1992;20(2):49-60.

11. Pilgram TK, Vannier MW, Hildebolt CF, Marsh JL, McAlister WH, Shackelford GD, et al. Craniosynostosis: image quality, confidence, and correctness in diagnosis. Radiology 1989;173(3):675-9.

12. Ridgway EB, Weiner HL. Skull deformities. Pediatr Clin North Am 2004;51(2):359-87.

13. Santos DT, Miyazaki O, Cavalcanti MGP. Clinical-embryological and radiological correlations of oculo-auriculovertebral spectrum using 3D-CT. Dentomaxillofac Radiol 2003,32:8-14.

14. Szklo M, Javier Nieto F. Epidemiology: beyond the basics. Gaithersburg, Md: Aspen; 2000.

15. Tubbs RS, Wellons JC $3^{\text {rd }}$, Salter G, Oakes WJ. Cranial deformation. Clin Anat 2003;16(5):450-2.

16. Vannier MW, Hildebolt CF, Marsh JL, Pilgram TK, McAlister WH, Shackelford GD, et al. Craniosynostosis: diagnostic value of three-dimensional CT reconstruction. Radiology 1989;173(3):669-73.

17. Vannier MW, Pilgram TK, Marsh JL, Kraemer BB, Rayne SC, Gado MH, et al. Craniosynostosis: diagnostic imaging with three-dimensional CT presentation. AJNR Am J Neuroradiol 1994;15(10):1861-9.

Received for publication on Sep 28, 2004 Sent for alterations on Dec 15, 2004 Accepted for publication on Feb 10, 2005 